\title{
The Shift from a Local to a Global Consumption Pattern in the Drivers of China's Luxury Consumption
}

\author{
Jiacheng Liu1, a, Carl A. Boger Jr. 2, b \\ ${ }^{1}$ Conrad N. Hilton college, University of Houston, Houston 77204, USA \\ ${ }^{2}$ Conrad N. Hilton college, University of Houston, Houston 77204, USA \\ aLiujiacheng221@gmail.com \\ bcboger@Central.UH.EDU
}

Key words: China's luxury market, China's contemporary luxury industry.

\begin{abstract}
This research paper aims to identify and discuss the main drivers of why luxury spending growth in China has moved from a local to more of a global consumption pattern. A PEST analysis has been applied to investigate China's contemporary luxury industry by separating the context into political, economic, social, and technological dimensions. A comprehensive and in-depth understanding of China's luxury market has been gained by examining China's luxury market reports and articles between 2011 and 2016 from Bain \& Company, McKinsey Company, and KPMG. The results of this investigation and analysis provide up-dated information and an understanding of the events in China's luxury market and consumption. This research is valuable for assisting and alerting global luxury companies in China to adapt to this new trend and rethink their marketing strategies in China. Additionally, this research will encourage further research into the domino effects triggered by this shifting pattern.
\end{abstract}

\section{Introduction}

1.1 Background. China's economy has grown astonishingly since the implementation of the Economic Reform and Opening-up Policy in 1979 (Morrison, 2015). With the rapid growth of the gross domestic product (GDP) during the last decade, China has become one of the major global economic powers (Morrison, 2015). McKinsey and Company (2013) predicted that the number of upper middle-class Chinese, defined as those with an annual income between 106,000 and 229,000 RMB, will be $54 \%$ of the population, in contrast to only $14 \%$ of the population in 2012 (Barton, Chen, \& Jin, 2013).

Due to China's rapid economic development and the growth in household disposable income during the past twenty years, China has also witnessed a dramatic change in luxury consumption (Atsmon et al., 2011; Luxury Market in China, 2015). The economic reports for 2015 reveal that 2015 witnessed the greatest amount of international luxury consumption, with Chinese consumers spending approximately 116.8 billion USD on luxury items, which accounted for $46 \%$ of the overall international luxury consumption.

However, according to Bain and Company's annual report (2015, para.1), "China's luxury market declined by $2 \%$ to 113 billion RMB in 2015". Simultaneously, approximately 91 billion of luxury goods were purchased outside China, which accounted for $78 \%$ of all Chinese luxury purchases in 2015 ("Purchase Aboard," 2015). The negative growth of luxury consumption in China in recent years and the shift in China's luxury market from a local to global consumption pattern has aroused both worldwide interest and concern.

1.2 Statement of the Problem. Previous articles (such as "China's Hotels," 2014; "China Crackdown Could," 2013; "Marketers Remain Bullish," 2015), state possible reasons for the sluggish luxury growth, including slower economic growth, turmoil in China's stock market, the anti-corruption campaign, and crackdown on governmental officials' extravagant spending. These may be some of the reasons for China's recent decrease in luxury consumption. Few of these essays use holistic or comprehensive methods to address other vital drivers which may have contributed to 
the phenomenon of China's luxury consumption shifting from a local to global consumption pattern.

These drivers include the increase in outbound Chinese tourists, the popularity of cross-border e-commerce, the upsurge in Chinese "Daigou," and the evolution of China's social media (Gorden, 2010; Liu \& Wang, 2014; Low, 2016; Xia, 2016). Therefore, this research aims to identify and discuss main drivers of why the luxury spending growth in China has moved from a local to more of a global consumption pattern. This research will offer readers up-dated information and an understanding of the events in China's luxury market and consumption. Secondly, it will also assist and alert global luxury companies in China to adapt to this new trend and rethink their marketing strategies in China. Thirdly, from an academic perspective, this research will encourage further research into the domino effects triggered by this shifting pattern.

\section{Literature Review}

\subsection{Political Dimension.}

2.1.1 Anti-corruption and campaign. China has been devoted to tackling corruption for the past thirty years. The recent anti-corruption campaign proposed by the current Chairman $\mathrm{Xi}$ has been considered the most effective, influential, and reverberated campaign (Li, Gong \& Xiao, 2016; Leggett, 2013). Chinese government officials are prohibited from spending extravagant amounts due to the strengthened anti-corruption law, legal enforcement, and continuous moral education. Many high-level Chinese officials have been arrested and convicted of corruption, accepting bribes, and transferring public funds (Abkowitz \& Fung, 2014).

Luxury consumption is greatly affected by this campaign because Chinese government officials are prudent and cautious of their spending in order to avoid any conspicuous consumption that may draw attention and cause them to be investigated. This has caused high-end five-star hotels in China to desire to become four-star hotels as Chinese government officials will not stay there if they are considered too luxurious. These luxury hotels that rely heavily on government business are now suffering from a loss of business ("China's Hotels Shed their Stars," 2014). Many Chinese government officials are now starting to spend their money overseas so that their spending may not be noticeable. This is one method of coping with the anti-corruption policy and prohibition of extravagant spending (Abkowitz \& Fung, 2014).

2.1.2 "Repatriating" consumers' spending. In the contemporary period, the Chinese government has been beleaguered by the challenge of Chinese luxury consumers transferring their purchase destination from the domestic market to overseas. Chinese consumers' overseas luxury consumption increased from 68\% in 2014 to 78\% in 2015 ("Can China's government," 2015). Such an accelerating trend, and the enormous volume of spending outflow that results, has made tackling this problem an urgent priority for the Chinese government. Multiple initiatives have been undertaken to encourage Chinese consumers to spend domestically. One such initiative includes the 19-new inbound duty-free shops that have been opened in an attempt to encourage Chinese consumers to spend inbound. Additionally, the Chinese government has approved 8 cities to establish trade zones, while also launching a favorable postal duty to facilitate the expansion of cross-border e-commerce (Xia, 2016). According to a study undertaken by ContactLab, the percentage of luxury spending abroad declined to $40 \%$ in the first four months of 2016, compared with the same period in 2015 (Liz, 2016).

2.1.3 Cracking down illegal smuggling "Daigou" activity. Bain \& Company estimated that annually, 55-75 billion RMB is spent through the "Daigou" channel in China, constituting approximately 50\% of China's entire luxury sales ("Will China's Government Put an End," 2015). Due to this massive grey market expanding exponentially, the Chinese government has affirmed its determination to crack down on illegal "Daigou" activity during 2015. Zhou Ting, the Fortune Character Institute's head and a Ministry of Commerce and Ministry of Finance consultant, conveyed the message that new regulations and policies will be implemented imminently, as a means of cracking down on those Daigou agents who smuggle in foreign goods without declaring the full and correct customs duties ("Will China's Government Put an End," 2015). 


\subsection{Economic Dimension.}

2.2.1 Slowing down economic growth. China's annual GDP growth rate averaged 9.76\% between 1989 and 2016 ("China GDP," 2017). The annual GDP growth rate eventually cooled down to $6.7 \%$ in 2016, following years of phenomenal growth ("Chinese Think Tank," 2017). Despite economic growth beginning to dwindle, Chinese consumers do not appear to be restricting their spending. All retail sales increased by $9.6 \%$ during 2016's first quarter, compared with the same period in 2015 ("China's consumers still kicking", 2016). The services sector has also witnessed a mean annual growth rate of $8 \%$ since 2012. Nevertheless, the luxury market has been hit by a slowing down of economic growth, with 2015 seeing a $2 \%$ decline in sales. Despite the overall economic circumstances showing deterioration, many luxury brands continue to thrive. Luxury industry professionals, such as LVMH's boss Bernard Arnault, believes that the Chinese economy has been underestimated, with the fundamentals being sufficiently stable to remain positive about the luxury market's future ("China's consumers still kicking", 2016).

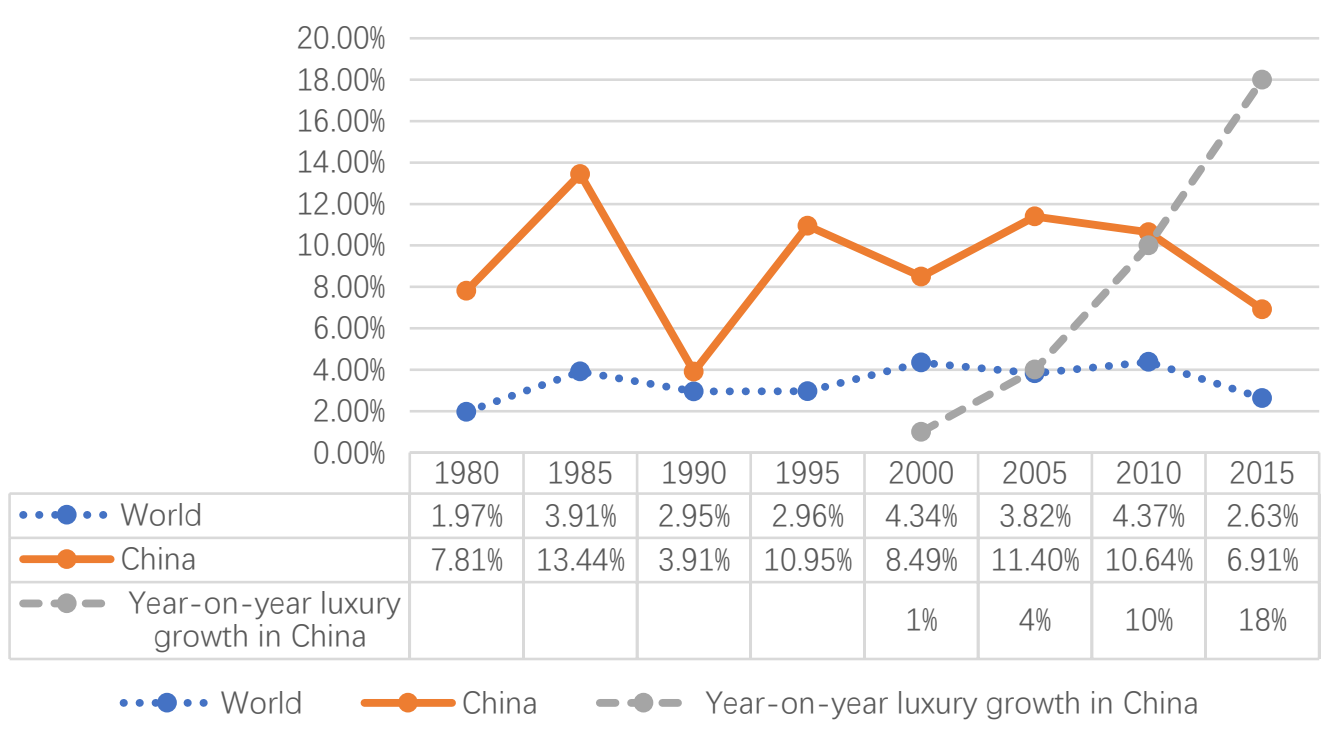

Figure 1. China's GDP growth compared with world's GDP growth from 1980-2015. Adapted from World Bank national accounts data, and OECD National Accounts data files, 2016, The World Bank Group, retrieved from

http://data. worldbank.org/indicator/NY.GDP.MKTP.KD.ZG?end=2015\&locations=CN\&start=1980. Copyright 2016 by The World Bank Group. Reprinted with permission.

Year-on-year luxury growth in China from 2000-2015. Adapted from "Luxury Goods Worldwide Market Study, Fall-Winter 2016" by D'Arpizio, C., Levato, F., Zito, D., Kamel, M., \& Montgolifier, J, Dec 2016, Bain \& Company, retrieved from http://www.bain.com/publications/articles/luxury-goods-worldwide-market-study-fall-winter-2016. aspx. Copyright 2016 by Bain \& Company. Reprinted with permission.

2.2.2 Rising middle class. During the late 1990s, China did not have a middle class, but in the 2000s, roughly five million individuals became middle class with annual salaries between 11,500 USD and 43,000 USD (China's middle class, 2016). Today bicycles are rarely to be seen and automobiles are pervasive. According to the article "Mapping China's Middle Class" from the McKinsey Quarterly (Barton, Chen \& Jin, 2013), China's upper middle class accounted for only 14\% of the population in 2012. This number is expected to increase to $54 \%$ by 2020 and will account for $56 \%$ of urban private consumption. This new middle-class group includes teenagers and people in their early 20s, which accounted for approximately 200 million consumers in 2012 and represented $15 \%$ of the urban consumption. Barton et al. (2013, para 7) predicted that "in ten years' time their share of urban consumer demand should more than double to 35 percent". These findings indicate 
that the middle class and upper middle classes in China are rapidly growing and the younger generations have become a major force in luxury consumption.

$100 \%=256$ million

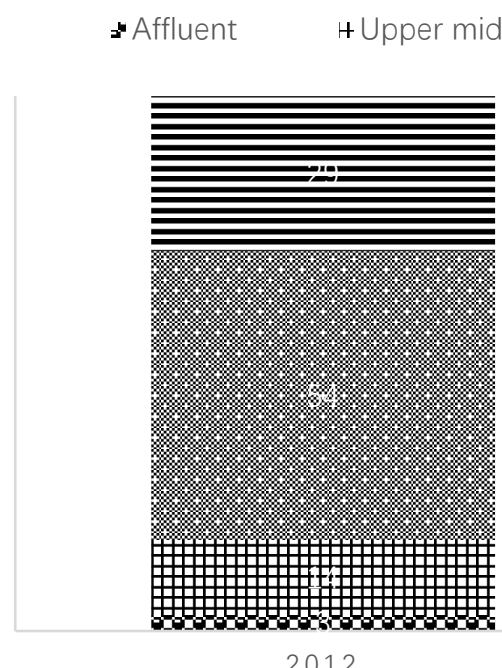

$100 \%=357$ million

Mass middle class $\quad=$ poor

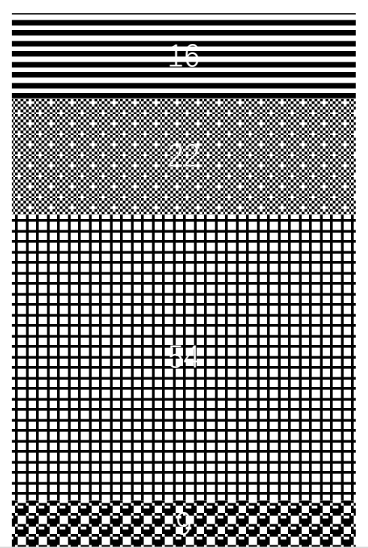

2022

Figure 2. China's Upper Middle-class Growth is Transforming the Nation. Adapted from "Mapping China's Middle Class", June 2013, Mckinsey \& Company, retrieved from

http://www.mckinsey.com/industries/retail/our-insights/mapping-chinas-middle-class Copyright 2013 by Mckinsey \& Company. Reprinted with permission Note. Defined by annual disposable income per urban household in 2010 real terms; affluent > 229,000 RMB (equivalent to > $\$ 34,000$ ); upper middle class, 106,000 to $229,000 \mathrm{RMB}$ (equivalent to $\$ 16,000$ to $\$ 34,000$ ); mass middle class, 60,000 to $106,000 \mathrm{RMB}$ (equivalent to $\$ 9,000$ to $\$ 16,000$ ); poor, $<60,000 \mathrm{RMB}$ (equivalent to < $\$ 9,000)$. Compound annual growth rate.

2.2.3 Rising number of millionaires. By 2015, there were 654,000 Chinese millionaires, which was a threefold increase of the number of millionaires since 2005. The estimated number of Chinese millionaires by 2025 stands at 1,144,500, which will be greater than the number of billionaires in the United Kingdom (The Wealth Report, 2016). Chinese consumers' incredible degree of expenditure on luxury goods is a direct consequence of an increasing number of Chinese individuals entering the upper middle class, in conjunction with the increasing number of affluent Chinese millionaires (Barton et al., 2013). Nevertheless, a Barclays' survey indicated that $47 \%$ of wealthy Chinese were planning emigration, whereas comparatively the average global rate was merely $29 \%$ ("Wealthy Chinese," 2015). Only 16 Chinese individuals received U.S. immigrant investor visas in 2004, which skyrocketed to 8,500 in 2014 , accounting for $85 \%$ of that year's entire applicants. The direct consequence of this explosion in the number of wealthy Chinese immigrant applicants has been a considerable depletion in China's substantial wealth, with 2.8 trillion RMB transferred overseas in 2011. 


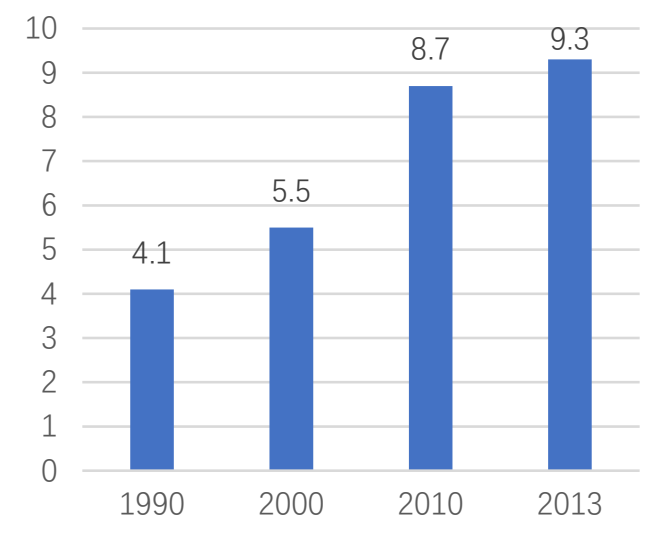

- Number of Chinese emigrants (millions)

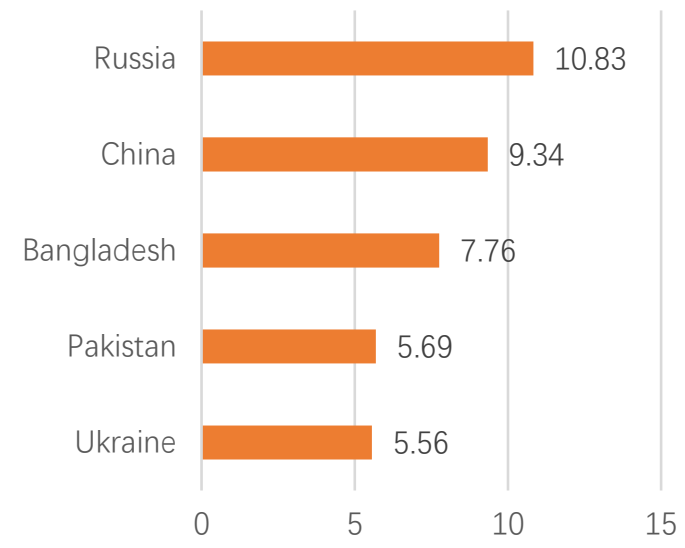

- Number of emigrants in 2013 (millions)

Figure 3. Chinese emigrants per year and countries of origin for emigrants worldwide. Adapted from "Wealthy Chinese Are Fleeing the Country Like Mad", Feb 2015, ChinaFile, retrieved from https://www.chinafile.com/multimedia/infographics/wealthy-chinese-are-fleeing-country-mad Copyright 2015 by ChinaFile

\subsection{Social Dimension.}

2.3.1 The unique characteristics of Chinese luxury consumers. Ngai and Cho (2012) classified the Chinese generations into three groups: The Cultural Revolution generation, who were born during the Cultural Revolution and are currently between the ages of 50 and 65; The transitional or mobile generation, who were in their early 20s when the Economic Reform started and are currently between 30 and 49 years old; and the one-child generation or "those who were born after Economic Reform and within the one-child policy".

The two younger generations have experienced the initial phases of China's Economic Reform, which caused the economy to rapidly grow. The younger Chinese generation were raised during a period when the material living standard greatly improved and the one-child policy was implemented. However, they have unfulfilled dreams passed on from their parents or grandparents, which instilled in them the value of achievement and success because their parents or grandparents did not have the opportunity to pursue their life goals due to the Cultural Revolution. The majority of the Chinese younger generation desires luxury consumption as a method of compensating for their earlier stresses and competition.

Now, $50 \%$ of Chinese luxury consumers are under the age of 35, in contrast to Western luxury consumers who are mainly dominated by senior individuals (Tsai, Yang, \& Liu, 2013). Chinese luxury consumers are more product-driven, while developed luxury market consumers have a greater preference for experience-seeking luxury consumption (Sun, Song \& Wang, 2011). Zhao and Belk (2007) explained that luxury consumption is a method for these individuals to demonstrate their increasing wealth and social status as well as indicates their achievements. Consequently, Chinese luxury consumers prefer conspicuous logos and brand recognition, which indicates that luxury consumption is driven by vanity (Lu, 2011; Hung, Chen, Peng, Hackly \& Rungpaka, 2011).

2.3.2 Unique motivations for luxury consumption. A major motivation for luxury consumption is status consumption (Nelissen \& Meijers, 2011). This can be elaborated as an attempt to elevate one's social status, which is derived from consuming conspicuous products (Eastman, Goldsmith, \& Flynn, 1999). Prendergast and Wong (2003) defined luxury consumption as 'consumers' desire for material possessions from a materialism perspective, which is driven by their wishes for as comfortable a life as their individual incomes allow" (Li, Sun, \& Zhang, 2015). However, income level does not significantly affect Chinese individuals' luxury consumption. The average individual income for Chinese families is $\$ 10,220$ in contrast to the household income of $\$ 47,300$ in the United States (Weagley, 2010). This comparative low individual income does not 
hinder Chinese luxury consumption. Chinese consumers still occupy the largest percentage of global luxury consumption.

Wang, Sun, and Song (2011) identified collectivism, face consciousness, social value, "guanxi", which can be interpreted as interpersonal ties in Chinese society, and cultural aspects of gifting as the main unique motivations for Chinese luxury consumers. This can adequately explain why Chinese customers annually invest in luxury consumptions, despite some of these customers lacking the required income to support their purchases.

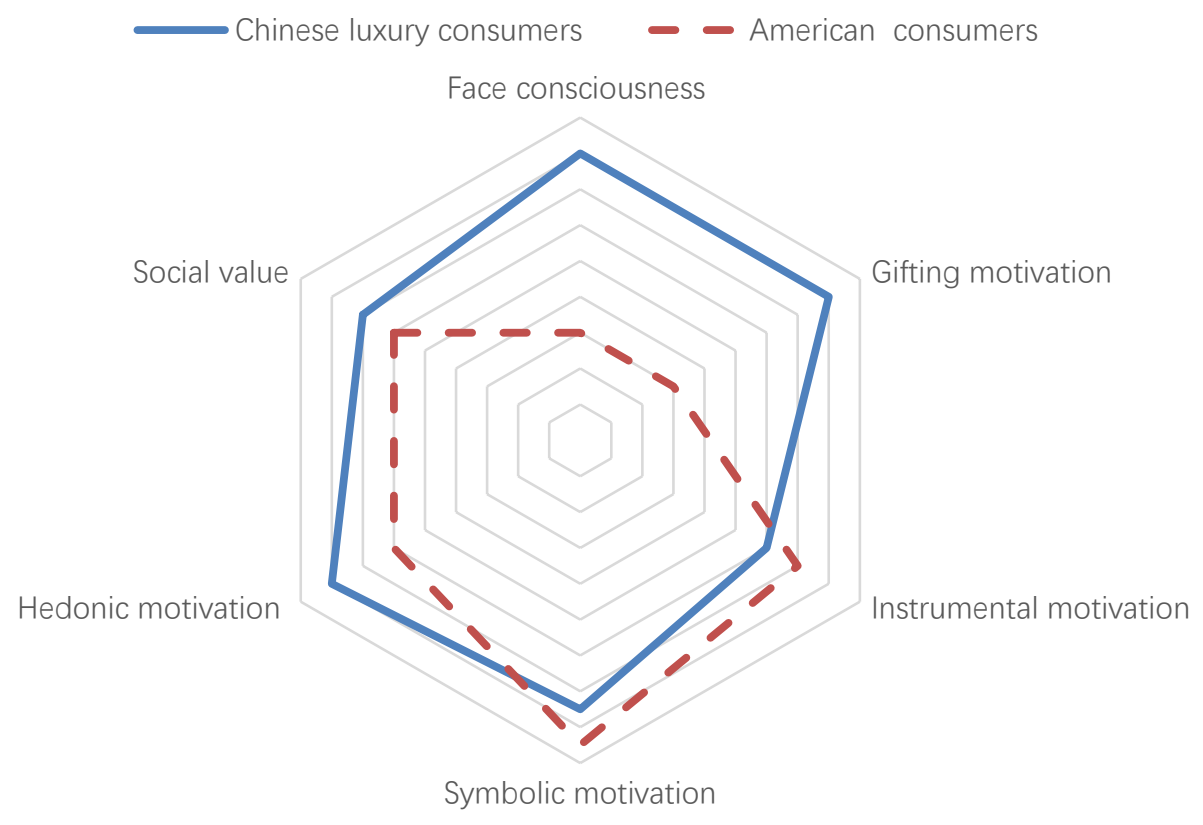

Figure 4. Luxury consumption motivations between China and U.S. Adapted from "Motivations of Luxury Consumption in America vs. China," by D. Yu, 2014, Graduation Theses and Dissertations. Paper 13854. Retrieved from http://lib.dr.iastate.edu/cgi/viewcontent.cgi?article=4861\&context=etd. Copyright 2014 by the Iowa State University. Reprinted with permission.

2.3.3 Online luxury consumption trend. McKinsey's research demonstrates that the younger generation of Chinese consumers are the most Westernized generation to date (Barton, Chen \& Jin, 2013). Unlike their parents and grandparents, who had limited abilities to utilize the Internet to gain information, this generation live in a world that is dominated by smartphones and the Internet (Beattie, 2013). They are more resourceful in utilizing the Internet and smartphones to search for information and they are more prone to seek other people's usage experience or comments on the Internet (Barton, Chen \& Jin, 2013).

Previous articles have shed light on the exponential growth of online and mobile luxury consumption by the Chinese younger generation, such as "Online, Mobile Luxury Spending" (2015). Tangible luxury products are not the only luxuries that are consumed online. Online luxury consumption also includes the consumption of intangible luxury services such as online hotel and restaurant bookings ("Online, Mobile Luxury Spending," 2015). A study conducted by KPMG revealed that $45 \%$ of Chinese respondents made most of their luxury consumption through the Internet and "the maximum amount they felt comfortable paying online for a single item is $\$ 660.8$, which was far higher than the \$298.9 indicated in a similar survey in 2014" ("Online, mobile luxury spending, 2015).

2.3.4 Outbound tourist shopping trend. A survey from Ipsos revealed that Chinese people are abandoning their traditional beliefs that traveling is extravagant and unnecessary and are instead embracing the idea that travel, especially outbound travel, is an important part of their daily lives. This new method of viewing traveling serves to enhance individuals' living standards, health, and substantially enhances families' disposable income, which has additionally caused a greater amount of Chinese international travelers. As a result, China has witnessed a dramatic growth in outbound tourism over the last decade (Zeng \& Go, 2013). 
According to the China Outbound Tourism Research Institute (2015), there were 10 million border crossings in 2000, which increased to 116 million in 2014. This upsurge in Chinese outbound tourists has caused massive outbound retail purchases. Nearly $58 \%$ of Chinese outbound tourists spent most of their budgets on shopping and spent $\$ 137$ billion on shopping in 2015, placing them at the top of the list followed by the U.S. and Germany, thereby contributing to a substantial portion of global luxury sales ("Market Research Report," 2014; "Report: Chinese Tourists," 2016).

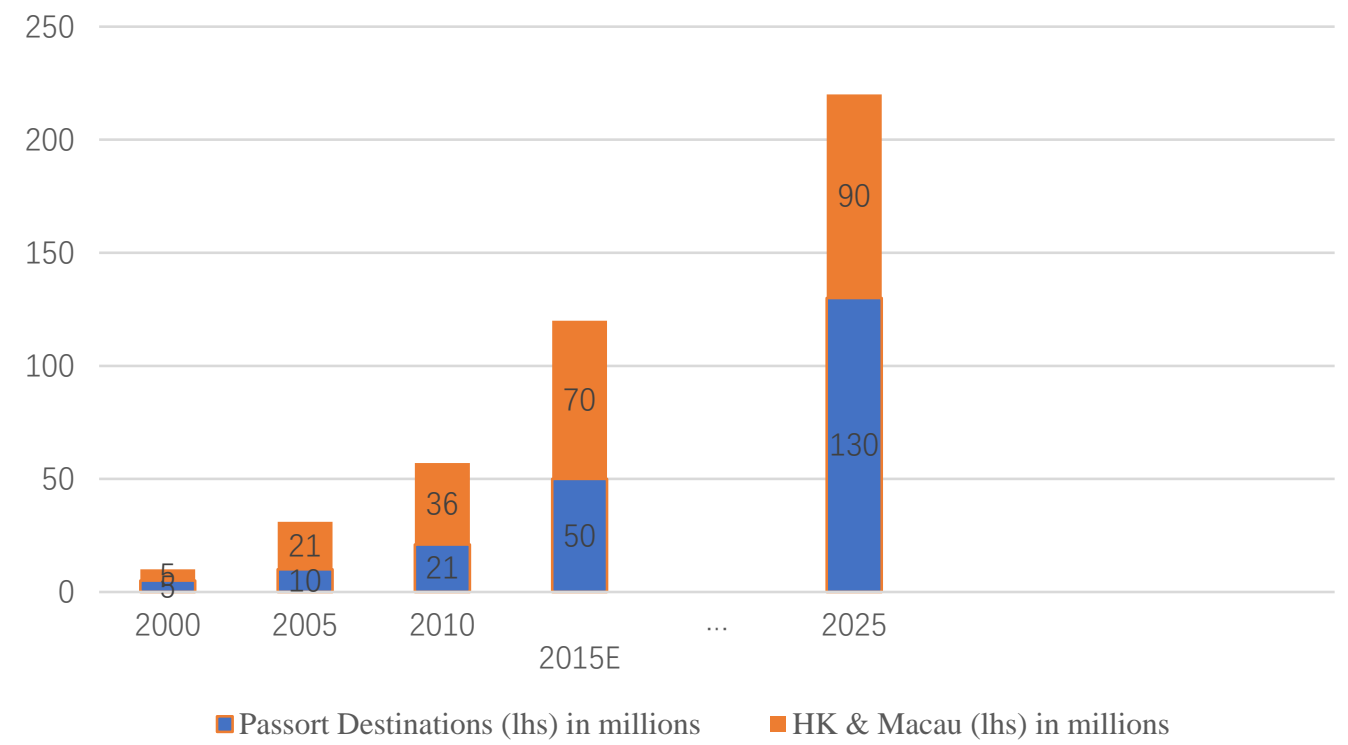

Figure 5. Chinese outbound tourists over time. Adapted from "The Chinese Tourism Boom", by S. Kawano, J. Lu, R. Tsang, J. Liu, Nov 2015, Goldman Sachs Global Investment Research, retrieved from

http://www.goldmansachs.com/our-thinking/pages/macroeconomic-insights-folder/chinese-tourist-b oom/report.pdf. Copyright 2015 by Goldman Sachs Global Investment Research. Reprinted with permission.
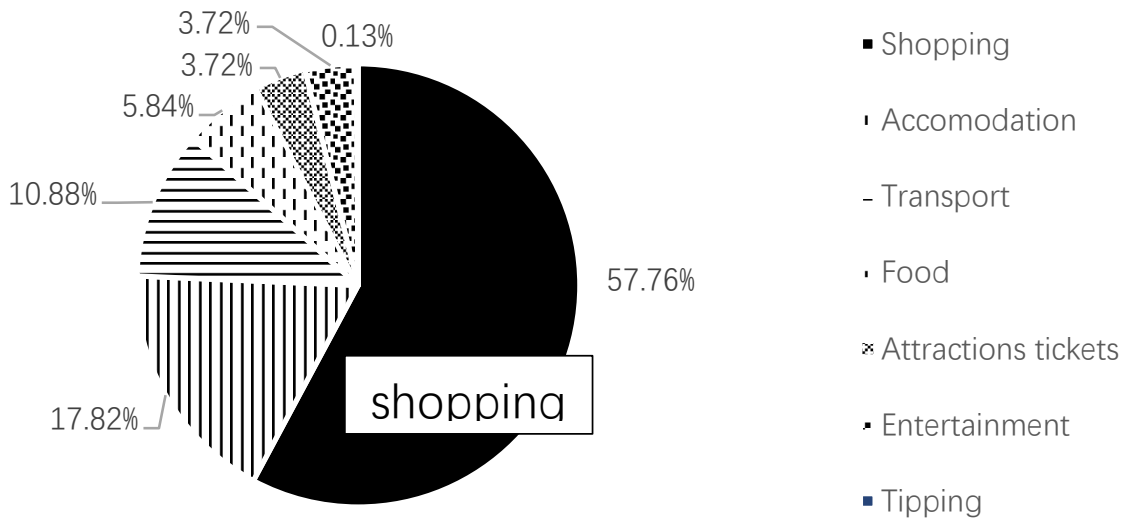

Figure 6. Chinese outbound tourists' spending preference. Adapted from "Rise of China Outbound Tourism", Sep 2014, China Internet Watch, retrieved from https://www.chinainternetwatch.com/8832/outbound-travelers/. Copyright 2014 by China Internet Watch. Reprinted with permission. 


\subsection{Technological Dimension.}

2.4.1 Social media technology in China. Social media was once considered simply a tool allowing people to create, share, and exchange information, ideas, pictures, and videos across virtual communities and networks. However, it has now developed into a powerful marketing device with a wide array of applications, for example connecting with other businesses and increasing revenue (Godey et al., 2016).

WeChat is China's most popular social media app, being the preeminent messaging app for sending texts, voice messages, and photos to friends and families (Lawrence, 2016). WeChat functions not simply as a chatting tool allowing individuals to text and send voice messages, it also acts as a portal, platform, and even a mobile operating system enabling users to hail taxis, order food, purchase film tickets, check-in for flights, transfer money to friends, book hotels, and pay utility bills. WeChat has an estimated 762 million monthly active users out of a total of over 1 billion registered users, indicating that it has a large market behind it. Consequently, this makes WeChat an ideal channel and platform for conducting business online ("WeChat is China's," 2015). WeChat's mean revenue per user has been estimated at a minimum of 7 US Dollars, seven times greater than WhatsApp's mean revenue per user, which is considered to be the largest messaging platform internationally (Chan, 2015). Ultimately, WeChat's functionality, in addition to its current 762 million monthly active users, provides an ideal platform facilitating "Daigou" (Pandey, 2016).

2.4.2 Chinese Daigou. "Daigou" is a Chinese word that refers to individuals who buy items overseas on behalf of mainland Chinese people who do not have the ability to shop globally, and usually a commission is charged (Battersby, 2016). Daigous are sensitive to daily discounts and promotions on items ranging from baby formula to luxury goods. Experienced Daigous will select brands and products based on the current trends in China and their market sense accumulated from previous experiences (Xu, 2016). They advertise or share information through their social media, such as WeChat and Webo, by posting and editing pictures of in-store inventory so that their customers will involuntarily see Chinese Daigous' posts, which thereby triggers purchasing motivations (Dong \& Hunt, 2014).

A dramatically increasing amount of Chinese people now choose "Daigou" as their preferred method of purchasing luxury goods due to the high price gap, relative fewer choices of luxury goods, and concerns about the quality of Chinese products. According to the China E-commerce Research Center, the Daigou market was worth approximately $\$ 12$ billion in 2013 , with an estimated $15 \%$ of luxury goods being purchased through "Daigou" channels. This number is forecasted to grow over the coming years ("Luxury Market," 2015).

2.4.3 Cross-border e-commerce. Cross-border e-commerce provides the tech-savvy younger Chinese generation with a channel for purchasing luxury products at a cheaper price through a novel online luxury consumption experience $(\mathrm{Xu}, 2015)$. The number of digital shoppers increased from 30 million in 2006 to 300 million in 2013 and more than half the digital shoppers were between the ages of 20 and 29 ("China Embraces Cross-border E-commerce," 2016). The number of cross-border e-commerce consumers is growing rapidly and is projected to reach 291.8 million in 2020. Bain and Company's 2015 China luxury market study (2015) highlighted that cross-border e-commerce is a major alternative luxury channel that is chosen by Chinese luxury consumers and is a crucial driver for the shift in China's luxury consumption pattern from local to global.

\section{Methodology}

3.1 PEST Analysis. This research evaluated mechanisms for systematically comprehending and explaining the reasons for the transition from local to global patterns in China's luxury consumption. A PEST analysis has been applied to thoroughly scrutinize China's luxury market, considering political, economic, social, and technological dimensions. A PEST analysis is an evaluation tool for examining macro-environmental factors as well as for facilitating an enhanced understanding of a particular organization or industry sector through an assessment of relevant and specific aspects of the business environment. 
3.2 Data and Information Collecting Procedure. The information is obtained from three world-leading consulting and analytic companies that specialize in providing luxury reports from a specific country scale to a global scale. The information and resources are mainly from Bain and Company and are supplemented by reports and articles from McKinsey Company and KPMG. This investigation utilizes the luxury accounts and essays about luxury purchases in China that were created by Bain and Company, McKinsey, and KPMG between 2011 and 2016.

\section{Results}

4.1 Growth of China's Luxury. Data and information obtained from these world-leading consulting and analytic companies affirm that the sluggish growth of the overall luxury market in China since 2011 is largely due to the slowing growth of the Chinese economy, which has partly been caused by the crackdown in corruption and the prohibition of extravagant spending by Chinese governmental officials. The future luxury market in China is estimated to recover due to the Chinese government's recent efforts and the future increase in the middle-class.

However, the anticipated future growth will no longer be as aggressive as it has been in the past. It has also confirmed that international consumption has rapidly increased as the Chinese customers' method of luxury consumption, which has resulted in a shift in the consumption pattern from local to global. This is the fifth consecutive year that over half the luxury consumption occurred outside mainland China since 2011 ("China luxury market," 2011, 2012, 2013, 2014, 2015).

Despite the recent declining Chinese currency, government efforts to control imports, and luxury brands' decreasing prices adjustments in China, overseas purchasing is continuing to be greatly favored by Chinese consumers. Outbound tourism shopping, "Daigou", and cross-border e-commerce have been underlined as the main channels for overseas purchases. The cost discrepancy between domestic and international purchases has caused Chinese luxury consumers to make purchases overseas. The quick development and wide employment of mobile devices and social media have provided technical support and operational convenience to Chinese luxury consumers to fulfill their luxury purchases at a significantly cheaper price.

Chinese luxury consumers are becoming sophisticated and resourceful within their luxury consumption. Chinese luxury consumers are showing more appreciation towards affordable luxury brands instead of blindly chasing after premium luxury brands. Chinese consumers consider products' design, quality, and personalization as well as prices for luxury goods. Additionally, an increasing number of Chinese luxury consumers have realized the price discrepancy between Chinese and overseas products. With numerous overseas luxury purchasing options available, they are more likely to fulfill their luxury consumption through overseas channels.

\section{Discussion}

\subsection{Influences from Overseas Purchasing Pattern.}

5.1.1 Employment opportunity. Chinese luxury consumers' overseas purchasing trends have a dominant role in both the Chinese and global luxury markets. The rapidly increasing overseas purchasing channels enable local Chinese luxury consumers to substantially save on luxury consumption due to the greater amount of product choices available. Additionally, overseas purchasing has also created substantial employment opportunities that benefit an incalculable number of Chinese individuals. Hundreds and thousands of e-commerce companies have been established and are thriving (Chang, Chen \& Dobbs, 2013). An increasing number of international packages have stimulated the expansion of delivery and logistics companies in both China and overseas (Lau \& Su, 2016). Numerous mobile phone applications specifically designed for "Daigou" and cross-border e-commerce have been developed and become platforms to facilitate transactions between "Daigou" and local Chinese luxury consumers (Peng, 2015).

5.1.2 Threat of counterfeits. However, oversea purchase also poses various intractable problems. Firstly, the popularity of overseas "Daigou" and cross-border e-commerce consumption creates opportunities for unscrupulous counterfeit producers to obtain profits. Many luxury 
counterfeit products have been manufactured, shipped outside China, and shipped to Chinese consumers in order to deceive local Chinese consumers. These products pretend to be luxury items from the actual brand and appear to be bought via international consumption platforms. These unscrupulous counterfeit producers even counterfeit various kinds of overseas purchasing receipts to make the local Chinese consumers more convinced that their purchases are genuine.

With counterfeit manufacturers substantially profiting, they have invested in methods to improve their counterfeit skills and techniques. The ever-improving counterfeit skills and techniques make it even harder for local Chinese luxury consumers to verify their purchasing channels and ensure that their purchased products are genuine. Additionally, global luxury brands are also impacted as they are losing a large amount of money while their brand images and reputation are being undermined due to the increase in counterfeits. Undoubtedly, overseas purchases provide local Chinese luxury consumers with an alternative method for economically purchasing luxury items. Counterfeit companies substantially weaken Chinese customers' attraction to local products. The development of counterfeit companies has serious implications for intellectual property and the establishment of a luxury market in China.

5.1.3 Threat of spending outflow. Secondly, the shift in luxury consumption from a local to global market indicates that capital is outflowing and that the Chinese government is losing a large amount of money that could be obtained from tax revenue.

Tax revenue declined from $7.8 \%$ in 2014 to $4.8 \%$ in 2015 , which encouraged the Chinese government to tighten its tax regulation on overseas purchases ("China tax on," 2016). The parcel tax that is imposed on international purchases has been increased since April, 2016, and this movement from the government indicates their attempts to level the competition between overseas and traditional luxury stores. This new tax regulation will also dissuade Chinese luxury consumers from purchasing luxury products through cross-border e-commerce and overseas "Daigou" channels. Another big impact on the luxury market in China from the Chinese government is the tightened restrictions on extravagant spending and corruption. The sudden deficit in money from government officials has caused international luxury companies in China to struggle to identify methods to correct this issue. They must actively attempt to seek new revenue instead of inactively depending on government purchases.

\subsection{The Future of Luxury Market in China.}

5.2.1 Repatriation of domestic luxury consumption. Although overseas purchases will likely continue to be overwhelming, it is plausible that the overseas purchasing trend's momentum can be curbed, with greater domestic spending expected in the future. This is due to luxury consumption by Chinese individuals abroad already declining by $3 \%$ in 2016, whereas Chinese individuals' domestic luxury consumption increased by $4 \%$, according to research by Contact Lab as well as Bain \& Company's luxury goods worldwide market study (Liz, 2016; D'Arpizio et al., 2016). With a much stronger crack down on illegal "Daigou" smugglers and further initiatives and incentives to encourage domestic spending, China's luxury market over the coming years is likely to witness a conspicuous rebound on domestic luxury sales.

5.2.2 Digital marketing. Enticing Chinese consumers through digital marketing will become an indispensable and powerful method for luxury brands in China. As an increasing number of the millennial generation enter the workforce, they are becoming the main group of individuals with purchasing power (Kuo, 2016). Consequently, their consumer behaviors are pivotal for luxury brands to investigate and focus on, in order to appeal to the millennial generation's preferences and tastes. Their heavy use and reliance on mobile technology and social media will provide an entrance to luxury brands seeking to reach and interact with this generation in a more effective and economical manner.

5.2.3 Sophistication of future Chinese luxury consumers. Chinese luxury consumers are becoming increasingly sophisticated (Atsmon, Dixit, \& Wu, 2011). They are showing greater appreciation for intangible luxury consumption, for example on spas or travelling and wellness activities, rather than purely conspicuous logos (Curran \& Scott, 2016). Tangible luxury products with unique designs, culture, history, and craftsmanship are becoming more appealing. Resultantly, 
incorporating more Chinese essence or imagery during the design of luxury products will be a major drive behind attracting Chinese consumers.

5.2.4 The Future of Chinese "Daigou". Purchasing luxury products through Chinese overseas "Daigou" platforms accounts for a huge portion of overseas purchases. The substantial price discrepancy between the Chinese and global markets has caused Chinese consumers to find overseas "Daigou". As the proliferation of overseas "Daigou" begin to dominate the luxury market in China, many global luxury brands have begun to experience a slump in their businesses. One substantial movement is that many global luxury companies have adjusted their pricing strategies in order to reduce the price gap between China and other countries. For example, Chanel's price modifications in March 2015 included increasing its prices in Europe by $20 \%$ while decreasing its prices by approximately $20 \%$ in China to greatly reduce the price gap between the Chinese and European markets (Guarino, 2015).

With more global luxury companies aligning their pricing strategies between China and other countries, the profit margin from reselling overseas luxury products to Chinese consumers will be minimal. Unfortunately, despite the various increasing challenges encountered by Daigous, such as the eradication of price discrepancies, increased government taxes, tighter restrictions on substantial purchases, and so forth, this platform will continue to thrive. Their years of accumulating a large local Chinese customer base and established trust and loyalty will be their biggest and unparalleled advantage. Selling more high quality and economical foreign products will likely be the future.

\section{Conclusion}

This paper has explored the current luxury market in China and consolidated key drivers for China's shift in luxury consumption from local to global. Despite many examinations shedding light on Chinese luxury consumption or luxury consumers, few examinations have touched on the domain of the recent luxury consumption outflow pattern. Therefore, firstly, this paper aims to reveal this pattern by providing comprehensive and updated information derived by utilizing content analysis on China's recent luxury annual reports. Secondly, the identified drivers and discussion on overseas purchasing trends can provide an informative insight into global luxury brands, which may help to reposition their marketing strategies in China. Finally, this paper expects that future studies will be conducted on the domino effects triggered by this shifting consumption pattern.

\section{References}

[1] Abkowitz, A., \& Fung, E. (2014, Aug 17). Chinese officials rush to sell luxury homes amid corruption crackdown. Wall Street Journal (Online). Retrieved from https://www.wsj.com/articles/chinese-officials-fearing-scrutiny-amid-crackdown-on-graft-rush-t o-sell-luxury-homes-1408316680

[2] Atsmon, Y., Dixit, V., \& Wu, C. (2011). Tapping China's luxury-goods market. McKinsey Quarterly, 1-5.

[3] Battersby, L. (2016). What is daigou. The Sydney Morning Herald. Retrieved from http://www.smh.com.au/business/innovation/what-is-daigou-20160614- gpixf4.html

[4] Barton, D., Chen, Y., and Jin, A. (2013). Mapping China’s middle class. Mckinsey Quarterly, 3, 54-60.

[5] Beattie, A. C. (2013). Marketers eye WeChat. Advertising Age, 84(8), 20-20.

[6] Chan, C. (2015). When one app rules them all: The case of WeChat and mobile in China. Retrieved from http://a16z.com/2015/08/06/wechat-china-mobile-first/

[7] Chang, E., Chen, Y., \& Dobbs, R. (2013). China's e-tail revolution. Mckinsey Quarterly, (3), 70-77. 
[8] China crackdown could hit luxury. (2013). WWD: Women's Wear Daily, 206(114),1.

[9] China's consumers still kicking. (2016). The Economist. Retrieved from http://www.economist.com/news/business-and-finance/21697597-free-spending-consumers-pro vide-comfort-troubled-economy-consumption-china-resilient

[10] China GDP annual growth rate. (2017). Trading Economics. Retrieved from http://www.tradingeconomics.com/china/gdp-growth-annual

[11] China embraces cross-border ecommerce. (2016). eMarketer. Retrieved from https://www.emarketer.com/Article/China-Embraces-Cross-Border-Ecommerce/1014078

[12] China gets tough with cross-border e-commerce and customs control. (2016). Jing Daily. Retrieved

from https://jingdaily.com/china-gets-tough-with-cross-border-e-commerce-and-customs-control/

[13] China's hotels shed their stars to lure newly frugal elite: Anti-corruption drive hits takings at Luxury retreats: Five-star properties 'are asking for downgrades'. (January 24, 2014). The Guardian. Retrieved from www.lexisnexis.com/hottopics/lnacademic

[14] China luxury market study 2013. (2013). Bain \& Company. Retrieved from http://www.bain.cn/pdfs/201312190719198977.pdf

[15] China's "second wave" of outbound tourists: New destinations and new consumption patterns. (2015). China Outbound Tourism Research Institute. Retrieved from http://www.itbkongress.de/media/itbk/ itbk_dl_de/ itbk_dl_de_itbkongress/ archiv_2015/itb_destination_days/Chinas_Second_Wave_of_outbound_tourists.pd 